\title{
CATION EXCHANGE RESINS IN THE TREATMENT OF OEDEMA
}

\author{
By A. A. G. Lewis, B.Sc., M.D., M.R.C.P. \\ Physician to the Connaught Hospital, Walthamstow, and the Fubilee Hospital, Woodford
}

It has been known for centuries that some insoluble and apparently inert substances could modify the composition of solutions. In $185^{\circ}$ Thompson and Way both suggested that aluminium silicates in soil were capable of transforming ammonium sulphate and carbonate into the corresponding calcium salts. In this century, substances with similar properties have been widely used in industry, notably for softening water. These are mainly silicates with a variable affinity for different ions: when associated with one they are capable of rapidly exchanging it for another for which they have a greater affinity, and are therefore known as ' ion exchangers.'

In $1935 \mathrm{Ad} i \mathrm{~ms}$ and Holmes reported that many synthetic resins possessed this property. In 1946 Dock fed rats on a cation exchanger to remove sodium from the gut. Since then many clinical studies of the use of cation exchange resins have appeared. Introductions to this subject and reviews have been written by Arnold (I95I), Dock and Frank (1950) and McChesney, Dock and Tainter (195I). A monograph on the subject of ion exchange has been written by Nachod (I949).

It is the purpose of the present article to review the recent literature on the subject and to include the report of a case in which resin therapy has proved successful.

The resins used for cation exchange have mainly been polymers of sulphonic or of carboxylic acid groups. They are insoluble but can absorb water, in which the hydrogen of the $-\mathrm{SO}_{3} \mathrm{H}$ or $-\mathrm{COOH}$ groups can be exchanged for other cations present in the solution. The resins have a varying affinity for different cations, an affinity that increases with increasing valency and atomic weight. It is therefore greater for calcium and magnesium than for potassium, and for potassium than for sodium. Under suitable conditions the resin may replace one cation in a solution by another, though the extent to which this occurs depends on several factors such as the relative concentrations, the $\mathrm{pH}$ of the medium and the time allowed for exchange.
Clinically, ion exchangers have been used for neutralizing the gastric juice (Marks 1949) and for removing sodium and potassium from the intestinal contents. Most of the published reports have dealt with their use for the removal of sodium as a means of treating oedema. For this purpose, either carboxylic or sulphonic resins can be given by mouth, in either the hydrogen or ammonium form. The latter is preferable in the case of the sulphonic resins as these have a very rapid rate of exchange and the replacement of sodium and potassium in the mouth by hydrogen is irritating to the mucous membrane. Carboxylic resins, on the other hand, are more palatable and more efficient in the hydrogen form.

The greater part of the exchange of cations appears to take place in the upper part of the alimentary canal and involves mainly the cations ingested in the food. For each $\mathrm{mEq}$ of cation taken up by the resin, I $\mathrm{mEq}$ of ammonium or hydrogen is exchanged and absorbed together with I mEq of anion. The ammonia is converted to urea, while the hydrogen ions are buffered by bicarbonate to form $\mathrm{H}_{2} \mathrm{CO}_{3}$, which is removed by increased pulmonary ventilation. The anions absorbed are now accommodated in the extracellular fluid at the expense of bicarbonate. The latter is lowered still further by loss of fixed base in the urine, but the kidney reduces this loss by secreting a highly acid urine (containing $\mathrm{H}_{2} \mathrm{PO}_{4}{ }^{1}$ in place of $\mathrm{HPO}_{4}{ }^{1}$ ) and, after a few days' delay, by forming a large quantity of ammonia. In this way ' disposable cations ' are absorbed in place of sodium, which is removed in the faeces. The corresponding anions are excreted by the kidney with little fixed base and with a minimum change in plasma $\mathrm{pH}$ (' compensated metabolic acidosis '). Such compensation cannot be effected if renal function is severely impaired: in this case sodium and other cations will be lost in the urine and severe acidosis will develop.

The amount of sodium removed in the faeces by a given dose of resin decreases with decreasing dietary sodium. As its bulk limits the quantity that can be given, there is a definite limit to the 
amount of sodium that can be removed and it is rare for the faeces to contain more sodium than the diet. As Page (I95I) has pointed out, resins are not a substitute for sodium restriction but an adjuvant to it. He found that whereas $45 \mathrm{~g}$. of a particular resin would remove $1.2 \mathrm{~g}$. of sodium from a diet containing $2.4 \mathrm{~g}$., I80 g. of resin were needed to remove $1.5 \mathrm{~g}$. of sodium from a diet containing $1.7 \mathrm{~g}$. Martz et al. (1952) found that each gramme of resin removed about I $\mathrm{mEq}$ of sodium ( $23 \mathrm{mg}$.) from a diet containing $3 \mathrm{~g}$. of sodium ( $130 \mathrm{mEq}$ ) a day. Similar figures have been given by other workers, though the type of resin, its state of division and the amount of other cations in the diet will all influence the actual quantity of sodium removed.

Even if sodium removal from the diet is not complete so that some of the ion is still being absorbed from the gut, the patient may lose oedema, for a variable amount of sodium may be excreted in the urine (particularly at the commencement of therapy, before renal ammonia formation is fully developed) while it is possible that sodium may also move into the intracellular fluid to replace potassium.

\section{Complications of Resin Therapy}

(I) Acidosis. A compensated metabolic acidosis develops in every case treated with cation exchange resins. In the great majority this produces no undesirable effects, though it is possible that it might play a part in producing skeletal decalcification over a long period, especially if hypocalcaemia were also produced. Klingensmith and Elkinton (1952), studying 34 cases of congestive failure treated with resins found the plasma chloride above I I $\mathrm{mEq} / \mathrm{l}$ and the alkali reserve below I $5 \mathrm{mEq} / \mathrm{l}$ in only one case, in which there was renal failure (plasma $\mathrm{pH}$ levels were not studied). Martz et al. used a resin of which 12 per cent. was in the form of an anion exchanger ("Carbo Resin,' Lilly) to increase the faecal excretion of anions and so lessen the compensatory acidosis, and found that the fall in plasma bicarbonate produced in one case by cation exchanger alone was reversed. Moreover, the mixture was found to be a more efficient sodium remover.

(2) Sodium Deficiency. The low salt syndrome may be produced if sodium removal is too drastic or if very much sodium is removed in the urine. Only 4 of Klingensmith and Elkinton's 23 patients who were maintained on resin for more than six months had plasma sodium levels of $130 \mathrm{mEq} / \mathrm{l}$ or less-the level at which this syndrome may occur. This sodium depletion may be associated with signs of cellular overhydration, vascular collapse and renal failure. If the kidneys cannot conserve sodium normally, very rapid sodium depletion may occur. Martz et al. have emphą sized that other factors contributing to oedem formation besides sodium retention must not bẹ forgotten. If there is hypoproteinaemia, drast sodium removal may lead to hyponatraemin before all the oedema fluid has disappeared, and they report hearing of two cases dying from the cause.

(3) Potassium Deficiency. This is particularl liable to occur with low sodium diets, for resings will then remove more potassium than sodium in the faeces. The simplest safeguard is to give extra potassium with the resin, i.e. to give $\dot{\text { dt }}$ partly in the potassium cycle. The potassium exchanged for hydrogen in the stomach and available for absorption in the intestine. three commercial preparations on which extended clinical trials have been made (Carbo Resin Katonium and Resodec) contain about one-thired of their bulk in the potassium cycle, and the risk of hypokalaemia with these is small. Howeven, there is still a danger that body potassium may be very slowly replaced by sodium. Emerson et at. (195I) found that in one patient after two years treatment (mainly with Resodec) $500 \mathrm{mEq}$ of potassium had been replaced by sodium and they consider that a further potassium supplengenf (1.5 g. $\mathrm{KCl}$ ) should be given daily.

(4) Calcium Deficiency. A few cases of chis have been reported (Greenblatt and Gilus 1948, Emerson et al. 1951, Friedman 1952), b this only appears to be a real hazard after veg long periods of treatment. Emerson et al. fourged that in 4 of their 5 cases the increase in sto@ calcium produced by the resin was negligib $E_{\text {. }}$ Lippman (195I) also concluded that this was negligible in I4 cases of the nephrotic syndrome though calcium balance studies were not madê. Klingensmith and Elkinton found no evidence of low serum calcium values in 9 patients after loug periods. Irwin et al. (1949) found that the faech calcium might decrease with treatment and also noted that there was no additional renal excretiogn of calcium. Martz et al. found no significañt changes in serum calcium, phosphorus or phosphatase or in the bone $\mathrm{X}$-rays in several cases. They did find, however, an average daily increase of $9.8 \mathrm{mEq}$ in the faecal excretion of calcium in 7 patients while on resin therapy. Mateer et al. (195I) studied four children with the nephrotic syndrome: a carboxylic resin did little to augmedt the effect of sodium restriction alone, and the low calcium values found were considered to be the result of the disease itself. They were net reduced further by the treatment.

In 1923 Salvesen and Linder noted the low serum calcium level in the nephrotic syndrome and in 1945 Emerson and Beckman drew attention 
to the low urinary calcium, high faecal calcium and deficient calcification of the shafts of bones in this condition. These cases appear to absorb extremely little calcium from the bowel: it was calculated that one child was storing only $2.85 \mathrm{~g}$. calcium per year, as against the normal $120 \mathrm{~g}$. for a child of his age. There is, therefore, as well as a low serum calcium which is at least partly the result of the low albumin, a deficiency of calcium absorption. With more advanced renal failure, low serum calcium levels are associated with high phosphate levels and secondary hyperparathyroidism.

It is possible to argue either that there is an inevitable tendency to low calcium levels and skeletal decalcification in renal disease which will hardly be aggravated by resin therapy, or that cases of the nephrotic syndrome are absorbing so little calcium that even a slight increase in the faecal loss of this ion must be avoided. To counteract this loss, should it occur, is not likely to be easy. Greenman et al. (195I) found that feeding the resin in the calcium cycle removed very little sodium, as would be expected. Friedman et al. (195I) recommended the addition of vitamins and calcium lactate to the diet, but this may reduce the amount of sodium removed by the resin. A more promising line of attack is suggested by the finding of Martz et al. that the inclusion of some anion exchanger increased the faecal excretion of phosphorus. This might make it possible to achieve higher serum calcium levels during therapy.

It must be remembered that if the kidney cannot form ammonia, extra losses of sodium, potassium and calcium in the urine may cause deficiencies of these ions. On the other hand, if renal failure or oliguria is present, hyperkalaemia may occur if a potassium resin is given.

(5) Anorexia and nausea, abdominal pain, diarrhoea, constipation and even faecal impaction have been noted in a few of the cases treated.

(6) Urinary casts nearly always appear when a very acid urine is being formed (Friedman et al. I95I), but there is no evidence that they impair renal function. A high fluid intake has been recommended.

(7) Deficiencies of iron, magnesium, thiamine and riboflavine might theoretically occur, but have not been reported. Martz et al. found a normal response to iron in one patient with hypochromic anaemia while on resin therapy.

\section{Advantages of Resin Therapy}

Several detailed studies of the use of resins for long periods in the treatment of congestive heart failure, cirrhosis with ascites and the nephrotic syndrome have been published. It is generally agreed that, when combined with moderate dietary sodium restriction, resin therapy will usually control oedema even when mercurial diuretics have failed to do so. In other cases it may reinforce the action of diuretics. Klingensmith and Elkinton treated 34 cases of congestive failure and found that oedema could be controlled in most of them even with some relaxation of dietary sodium restriction. Treatment was effective in 13 out of 15 cases who had previously remained oedematous despite all therapy; in 5 cases it wholly or partly replaced mercurial diuretics while it was effective in 5 cases out of 6 who were sensitive to mercury. Martz et al. treated 42 patients with congestive failure and 14 with cirrhosis and ascites with Carbo Resin for more than four months and considered treatment to be effective in all but 6. Lippman (195I) treated I I cases of the nephrotic syndrome successfully. Payne and Wilkinson (195I) treated 6 cases of this syndrome, but thought that resin therapy had little effect on ascites.

It appears, therefore, that in very many cases oedema can be controlled by the use of resins without restricting the salt in the diet to the point where it becomes utterly unpalatable, and without the use of injections. In other cases resin therapy does not replace the latter, but increases their effectiveness. The risk of serious complications occurring under proper supervision? appears to be a small one to set off against the very great advantages of this therapy.

The following report of a case treated for six months by resins shows the possibilities of this form of therapy in a suitable case.

Patricia B., aged II $\frac{1}{2}$, was admitted to the Connaught Hospital in August $195 \mathrm{I}$ with the history of a sore throat a month previously, followed by cloudy urine and swelling of the face and legs. The urine contained albumin, red cells and hyaline and granular casts. The blood pressure was $140 / 80$ and the fundi normal. Blood urea was $39 \mathrm{mg}$./ $/ 100 \mathrm{ml}$. and haemoglobin 63 per cent. Culture of a throat swab grew nonhaemolytic streptococci and she was given courses of penicillin and chloramphenicol.

A fortnight later the urinary content of albumin was $7 \mathrm{~g}$./l. and oedema was more marked. The total plasma proteins were $4.2 \mathrm{~g}$. and the blood cholesterol $305 \mathrm{mg}$. per cent. The child was treated with a salt-fee diet (sodium content less than $500 \mathrm{mg}$. daily) without protein restriction and with extra fruit and carbohydrate. An alkaline mixture, vitamins, thyroid and iron were given, but the oedema increased and she became apprehensive and miserable. She found the diet unpalatable and it became increasingly difficult to make her eat it. The urinary abnormalities 
persisted. By the end of 1951 the blood pressure had risen to $180 / 115$ and the blood urea to 48 $\mathrm{mg}$./ $100 \mathrm{ml}$., and the plasma proteins had fallen to $3.2 \mathrm{~g}$. per cent. (albumin $2 \mathrm{~g}$. per cent.). In spite of adding to the diet large quantities of Casilan (which provides a high protein, salt-free supplement), the oedema persisted and the albuminuria constantly exceeded $10 \mathrm{~g} . / 1$.

The child was unhappy, unco-operative and anxious to go home. It was therefore decided to give a short course of resin therapy in an attempt to reduce the oedema. The low sodium diet, with $100 \mathrm{~g}$. Casilan daily, was continued, and I6 g. of Carbo Resin (Lilly) were given in fruit juice three times a day between meals. (This is a carboxylic resin containing 12 per cent. as an anion exchanger and the rest cation exchanger, one-third in the potassium and the rest in the hydrogen cycle.) The child was weighed daily. After five days the weight began to fall, when the dose of Carbo Resin was halved. Three weeks later the weight had fallen from 8 st. $2 \mathrm{lb}$. to $6 \mathrm{st}$. and the child appeared mentally and physically transformed. She had slight oedema of the face and legs only, and she was happy and optimistic. The urinary abnormalities were unchanged. The plasma chloride was $105 \mathrm{mEq} / 1$ and the bicarbonate $22 \mathrm{mEq} / \mathrm{l}$. The blood urea was $54 \mathrm{mg}$./100 $\mathrm{ml}$. Electrocardiograms showed no evidence of any disturbance of plasma potassium.

Resin therapy had proved so successful that it was decided to allow the child to go home. An attempt was made to find a small dose which would enable her to live a more or less normal life at home, as the prognosis was clearly very poor. The parents were extremely anxious to co-operate, and the following regime was suggested:-

I. A diet cooked without salt and with no salt added. Salt-free bread and butter. Shredded wheat for cereal. Extra fruit and salad. No other restrictions.

2. Weekly weighing.

3. 5 to $15 \mathrm{~g}$. of resin daily, according to the weight trend.

4. Avoidance of undue chill and fatigue, with a rest after dinner.

In the six months that followed the child remained remarkably well. She went to school for the summer term, and enjoyed a holiday at the seaside. She is so active that her mother has had difficulty in making her rest. She has grown nearly two inches in height. The breasts are enlarging and some pubic hair has grown, though menstruation has not yet begun.

During this time the weight has fluctuated between $6 \frac{1}{2}$ and 7 st. Attempts to increase the diet have led to an increase in weight; for instance, an extra pint of milk a day caused her to gai nearly a pound a week for six weeks. Regulas electrocardiograms and estimations of the plasma chloride and bicarbonate have shown no signifi cant changes and after six months' therapy the following levels were reported:

$\mathrm{Hb} 70$ per cent., plasma chloride IoI $\mathrm{mEq} / \mathrm{L}_{\mathrm{B}}$ bicarbonate $23 \mathrm{mEq} / \mathrm{l}$, sodium $134 \mathrm{mEq} / \mathrm{l}$, potas sium 5.1 mEq/1, calcium $8.3 \mathrm{mg}$. $/ 100 \mathrm{ml}$., phos phorus $4.3 \mathrm{mg}$./100 ml., alkaline phosphatase 16.9 K.A. units, proteins $4.5 \mathrm{~g} / 1 \mathrm{rco} \mathrm{ml}$. (albumin $2.7 \mathrm{~g}$ I00 ml.), cholesterol $465 \mathrm{mg} . / \mathrm{Ico} \mathrm{ml}$., urea 63 mg./ $100 \mathrm{ml}$. X-rays of the hands showed ng evidence of rickets or of decalcification.

The blood pressure was $145 / 95$ and the fund normal. There. is still some swelling of the face in the morning, and slight pitting oedema of the legs, but no attempt has been made to reduce heit to a theoretically ideal ' dry weight.'

It appears that a simple regime for the child has been found, and it seems unlikely that the absence of gross oedema is due to any essential change in the condition of the kidney itself, fo the blood cholesterol has risen, the blood pressure has fallen, the abnormal levels of plasma an屯 urinary albumin remain and the child gains weight when she takes more salt.

The smallness of the successful dose may for some comment. It appears to be due to fact that the kidney is excreting moderate amounts of sodium. Analysis of a 24-hour specimen os urine showed that $31 \mathrm{mEq}$ of sodium, 80 od potassium and $35 \mathrm{mg}$. of calcium were being ex creted in 24 hours. No estimations of faecaP sodium have been made, but the dose of resi used probably removes a further 5 to $15 \mathrm{mEq}$ a day by that route. It could almost certainly be increased if necessary without serious consequences, but it would be unwise to give mucl larger doses for, long without obtaining furthe? information of the ammonia-forming power of the kidney.

It is interesting to observe the very low level of urinary calcium. The possibility that this would be increased to spare the excretion of sodium, in spite of the serum calcium level being at about the 'threshold' level, has not materialized. The level of serum calcium is normal for this level of the albumin. Further studies of this child's calcium absorption are being made, and will b尺 reported elsewhere.

I am greatly indebted to Dr. Bruce Young senior physician to the Connaught Hospital, fofe permission to study this case; to Sister Lawrence for her careful management of the diet and weighing; and to Dr. H. Caplan for the patho $\frac{0}{0}$ logical investigations. The Courtauld Institute of Biochemistry kindly estimated the serum and 
urine sodium and potassium by means of a flame photometer.

\section{BIBLIOGRAPHY}

ARNOLD, W. P. (195I), New Eng. F. Med., 245, 33 I.

DOCK, W. (1946), Trans. Assoc. Amer. Phys., 59, 282.

DOCK, W., and FRANK, N. R. (1950), Amer. Heart F., 40, 638. EMERSON, K., and BECKMAN, W. W. (1945), f. clin. Invest., 24, 564.

EMERSON, K., KAHN, S. S., VESTER, J. W., NELSON, K. D. (195I), Arch. Int. Med., 88, 605 .

FRIEDMAN, I. S., ZUCKERMAN, S., and COHN, T. D. (1951), Amer. F. Med. Sci., 221, 672.

FRIEDMAN, I. S. (1952), Arch. Int. Med., 89, 99.

GREENBLATT, I. J., and GILWOOD, M: E. (1948), quoted by Emerson et al.

GREENMAN, L., PETERS, J. H., MATEER, F. M., WEIGAND, F. A., WILKINS, D., TARAIL, R., RHODES, G., and DANÖWSKI, T. S. (I95 I), F. clin. Invest., 30, 995.
IRWIN, L., BERGER, E. Y., ROSENBERG, B., and JACKENTHAL, R. (1949), $\mathcal{F}$. clin. Invest., 28, 1403 .

KLINGENSMITH, W. C., and ELKINTON, J. R. (1952), Circulation, 5, 842.

LIPPMAN, R. W. (1951), Arch. Int. Med., 88, 9.

MCCHESNEY, E. W., DOCK, W., and TAINTER, M. L. (1951), Medicine, 30, 183 .

MARKS, J. A. (1949), Rev. Gastroenterol., 16, 82.

MARTZ, B. L., KOHLSTAEDT, K. G., and HELMER, O. M. (1952), Circulation, 5, 524.

MATEER, F. M., ERHARD, L. H., PRICE, M., WEIGAND, F. A., PETERS, J. H., DANOWWSKI, T. S., TARAIL, R., GREÉNMAN, L. (1951), $\mathcal{f}$. clin. Invest., 30, 1018.

NACHOD, F. C. (1949), 'Ion Exchange: Theory and Application,' New York Academic Press.

PAGE, I. H. (1951), F. Amer. Med. Ass., 147, 1311 .

PAYNE, W. W., and WILKINSON, R. H. (i95I), Lancet, ii, ror.

SALVESEN, H. A., and LINDER, G. C. (1923), f. biol. Chem., 58,617 .'

THOMPSON, H. S. (1850), F. Roy. Agr. Soc., England, II, 68.

WAY, J. T. (1850), Ibid., 11, 313.

\section{OCCUPATIONAL THERAPY FOR LONG TERM PATIENTS IN BED}

By MARY S. Jones, M.C.S.P., M.A.O.T. Senior Occupational Therapist; Slough Industrial Health Service; Farnham Park Recuperative Home

\section{Aims of Treatment}

Prolonged rest in bed is sometimes prescribed for patients as a form of treatment, in the hope that the condition needing this treatment will eventually be cured or arrested, and that the patient will return to the outside world with as little residual disability as possible. To ensure this, medical and surgical treatment must be accompanied by a programme of occupation which will maintain the patient's physical capacities as far as may be compatible with the prescribed position of decubitus, and which will increase the mental capacity to the uttermost to make up for limitations which may be set by physical disability. The patient must be kept happy and contented so that as far as possible nervous strain may be avoided and, at the same time, ambition fostered so that the patient will be prepared and eager to undertake the responsibilities of normal life.

\section{Anxieties for Future Employment}

Anxiety about earning a livelihood in the future is often considerable and adds to the nervous strain of a period of forced inaction, making a patient restless and miserable. In prescribing occupational therapy for these people the surgeon or physician should indicate the probable period of incapacity and give- some prognosis of the degree of physical disability expected. Then, in consultation with the almoner, some tentative plans can be considered by the patient for his future employment. If his previous work is obviously not going to be suitable and retraining for another will be necessary; the programme of occupation should be planned to include some preparation for the chosen training. If a patient is shown that he can use the period of physical inaction to good effect and begin at once to prepare himself for a new job, he will be more likely to settle down without excessive fretting and he will be in a better frame of mind to receive medical or surgical treatment.

\section{Preparatory Training for Employment}

It may be obvious that a carpenter or bricklayer with spinal caries will not be able to go back to his old job. But this man will appreciate that a sound knowledge of woodwork or bricklaying would be useful to a builder's clerk. He may therefore be persuaded to embark on a correspondence course in bookkeeping which will be 